\title{
Health and living conditions in social housing: comparison between rehabilitated and non-rehabilitated neighbourhoods
}

\author{
Sara Soares ${ }^{1} \cdot$ Sandra Brochado $^{1} \cdot$ Nuno Ramos ${ }^{2} \cdot$ Raquel Duarte $^{1} \cdot$ Pedro Norton $^{1}$. \\ João Delgado $^{2} \cdot$ Sílvia Fraga $^{1}$
}

Received: 3 December 2015 / Accepted: 12 July 2016 / Published online: 6 August 2016

(C) Springer-Verlag Berlin Heidelberg 2016

\begin{abstract}
Aim Our aim is to compare how residents from two social housing neighbourhoods of Porto City, one rehabilitated and one non-rehabilitated, perceived their living conditions, health and quality of life.

Subjects and methods A cross-sectional study was conducted, selecting residents from two social housing neighbourhoods of Porto City, one rehabilitated and another one non-rehabilitated. The information was collected through quantitative (a structured questionnaire; $n=82$ ) and qualitative face-to-face interviews administered by trained interviewers $(n=16)$.

Results No significant differences were found between populations from both neighbourhoods regarding social, behavioural and health characteristics. The major differences among neighbourhoods were found on variables such as satisfaction with house, the need of rehabilitation work, and the absence of mould and dampness in the house $(p<0.001)$ as well as pollution $(p<0.05)$. Qualitative data showed that residents from the rehabilitated houses were pleased not to have been moved to another location and were very satisfied with the rehabilitation work, which in their perception contributed to the residents' wellbeing. Nominal and ordinal variables were
\end{abstract}

Electronic supplementary material The online version of this article (doi:10.1007/s10389-016-0751-6) contains supplementary material, which is available to authorized users.

Sara Soares

sara.soares@ ispup.up.pt

1 EPIUnit - Institute of Public Health, University of Porto, Rua das Taipas, 135, Porto 4050-600, Portugal

2 CONSTRUCT-LFC, Faculty of Engineering (FEUP), University of Porto, Porto, Portugal described using proportions and compared using the chisquare test. Quantitative continuous variables were presented as a median (percentile 25 to percentile 75 ) and they were compared via the Mann-Whitney test.

Conclusion Public economic and financing resources should be redirected to social housing rehabilitation that, although in the short term does not have a direct impact on health savings for the occupants, is an important dimension of the residents' sense of wellbeing and satisfaction.

Keywords Social housing rehabilitation $\cdot$ Neighbourhoods rehabilitation $\cdot$ Quality of life $\cdot$ Living conditions

\section{Introduction}

European citizens spend $90 \%$ of their time indoors (Fernandes et al. 2009; Molhave and Krzyzanowski 2000). A previous study showed that the overall mean time spent at home by Germans is $15.7 \mathrm{~h} /$ day, similar to the Americans $(15.6 \mathrm{~h} /$ day $)$ and to the Canadians $(15.8 \mathrm{~h} /$ day; Brasche and Bischof 2005). Although there is no data available for Portugal, we may assume that Portuguese spend a considerable time indoors as indicated in other countries, emphasizing that the quality of the indoor environment is a crucial factor to health and wellbeing of the residents (Muhič and Butala 2004; Wilkinson 1999). Also, housing conditions are included in the national action plans on social inclusion of the new member states of European Union (Eurofound 2006), and quality of housing has a significant role in determining general life satisfaction, even when other factors, such as income, are taken into consideration (Doman'ski et al. 2006). However, housing conditions are still very dependent on the owners and/or residents economic resources (Hopton and Hunt 1996; Thomson et al. 2001). Aspects such as thermal comfort, indoor air 
quality, acoustics and illuminance rely on the design and operation of building systems and play a major role in the quality of the indoor environment (Ncube and Riffat 2012), and consequently on peoples' quality of life (Doman'ski et al. 2006).

Indoor environment presents significant exposures that might worsen the health of residents (Bluyssen and Cox 2002; Fernandes et al. 2009; Ncube and Riffat 2012; Wu et al. 2007), namely asthma, allergies, lung cancer and other respiratory and cardiovascular diseases through exposure to allergens (moulds) and chemical products (Bluyssen and Cox 2002; Fernandes et al. 2009; Ncube and Riffat 2012). Likewise, a higher prevalence of poor indoor hygrothermal conditions is expected in social housing that is typically occupied by populations from a lower social strata who may not be able to support the high operating costs associated with the technology of indoor and vehicular environmental comfort (HVAC: heating, ventilating, and air conditioning) ( Doman'ski et al. 2006; Northridge et al. 2010; Ruel et al. 2010).

In addition, living in social housing has also been associated with high unemployment and school dropout rates, and with high proportions of crimes and vandalism (Jargowsky 2001). Therefore, the importance of social housing, often discredited and associated with a political and social failure, should be a major element of the urban management and public policy (Greenbaum 2002).

It has been discussed within the context of the United States, for instance, as to whether relocation of social housing residents into private market rental housing (with help of voucher subsidies) might be the solution (Oakley and Burchfield 2009; Popkin and Cunningham 2002). If people were removed from the social housing and paid to move to a private neighbourhood, the problem of "concentration of poverty" would be solved. However, there is no evidence as to whether former social housing residents tend to experience improvements in their quality of life when they move to different neighbourhoods (Soloman 2005). In fact, uprooting people from their homes seems to negatively impact residents' health, showing signs of rapid worsening over time, mainly among the oldest (Kleit and Manzo 2006; Tester et al. 2011).

In Portugal, especially in the late 1990s, several programs to relocate low-income families in newly built social housing neighbourhoods were promoted and their former neighbourhoods were demolished since their constructive features were very poor. It has been debated that this reallocation process may have impacted on social networks and therefore on wellbeing (Keene and Geronimus 2011; Tester et al. 2011). Relocation may disrupt geographically rooted social ties that are anchored within social housing neighbourhoods (Keene and Geronimus 2011). In more recent years, the old social housing neighbourhoods, built mainly in the late 1970s, were pressing for solutions due to evident degradation and inadequacy to user demands. An option for rehabilitation has been made in most of these cases.
A large social housing rehabilitation program is ongoing in Porto, a northwest city of Portugal, one of the major urban areas in Southwestern Europe. This program offers an enormous contribution for the social housing residents that are unable to cover the substantial costs involved in house improvements that would help to avoid reallocation and changing of social ties.

However, the social building rehabilitation program is dependent on public funding in a context of financial restrains, and thus the investment should be proven to be associated with better health indicators, energetic efficiency and cost-effectiveness. Therefore, the present study aims to compare how residents from two social neighbourhoods - one rehabilitated and one non-rehabilitated - perceived their living conditions, health and quality of life.

\section{Methods}

The project "Influence of Indoor Hygrothermal Conditions on Human Quality of Life in Social Housing" combines the areas of expertise including engineering, medicine and public health, to approach health and living conditions of social housing residents. The study design and sample have been fully described elsewhere (Soares et al. 2015).

Ethical approval was granted by the Ethics Committee of Institute of Public Health of University of Porto and by the Portuguese Data Protection Authority. All participants formalized their collaboration through a written informed consent according to the World Association's Declaration of Helsinki.

\section{Participants}

Residents from two social housing neighbourhoods of Porto City, one rehabilitated and another one non-rehabilitated, were selected. These two neighbourhoods were both built in the late 1970s, sharing the same building typology, and most of the residents from the two neighbourhoods moved there at approximately the same time.

Given that the in situ measurements were taken over 1 year requiring the installation of individual temperature and relative humidity dataloggers in the bedrooms and living rooms of each house, only 50 houses were selected -25 from the recently rehabilitated neighbourhood and 25 from the nonrehabilitated neighbourhood. The selection of the analysed dwellings took different aspects into account, namely physical aspects of the dwellings, number of occupants and demographic composition of the family. The dwellings included in the sample needed to cover different design factors, which means that some would be located in the core of the building, while others would have a gable wall and be located just below the roof or on the ground floor. All residents 18 or older were invited to participate in the survey. Next, each eligible 
resident was contacted and invited to participate in the interview by telephone. Upon agreement, a visit for questionnaire fulfilment was scheduled at the time and day considered as more appropriate by respondent. Further information about the study was given verbally, upon request, by the trained interviewers. The participation of 46 residents ( $75 \%$ of participation) from the non-rehabilitated neighbourhood and 36 residents $(62 \%$ of participation) from the rehabilitated neighbourhood was obtained for the study.

\section{Data collection}

Information was collected through quantitative and qualitative face-to-face interviews administered by trained interviewers, between September 2014 and January 2015.

\section{Questionnaire}

A structured questionnaire assessed information on age, school education (no degree, finished elementary school, middle school or higher), and employment status (employed, unemployed, retired or other), household income, perceived income adequacy (it is hard or very hard to live with current income, current income is sufficient or allows to live comfortably), health behaviours (smoking status and alcohol intake), clinical history (doctor diagnosis of chronic diseases), health care visits, medication, and quality of life. Quality of life was assessed by the 36-item short-form (SF36), a short questionnaire developed as part of the Medical Outcomes Study. It was designed as a generic indicator of health status for use in experimental studies and includes eight sub-dimensions that assess different areas of health: physical function, physical performance, body pain, general health, mental health, emotional role, social function and vitality. The items use the Likert scale, from 0 to 100 , with 100 corresponding to better quality of life (Ware and Sherbourne 1992); furthermore, participants were asked about the house (house conditions, satisfaction and needs) and neighbourhood characteristics (amenities, and perceived security, social support and reciprocity).

\section{Interview}

Additionally, a qualitative interview was conducted only among the residents from the rehabilitated neighbourhood in order to understand the self-perception of living conditions and their influence in health and quality of life, and also, the effect of building refurbishment on residents' perception of quality of life. Participants were selected based on gender, age and occupation (employed, unemployed and retired) and 16 interviews were conducted. After the questionnaire was filled and deemed sufficient, respondents were asked for their interest in being interviewed and were later contacted by phone to schedule the interview, which took place at the residents' household. The interview guide was designed to cover the experience of living in social dwellings. Main topics of the interview were the experience of living in social housing and neighbourhoods, the perception of quality of life, and perception of house and building construction solutions.

\section{Data analysis}

We used a combined approach of quantitative data provided from the structured questionnaire with qualitative data provided by interviews. A descriptive analysis was conducted using the Statistical Package for the Social Sciences 22.0 software (SPSS $®)$. Nominal and ordinal variables were described using proportions and compared by the chi-square test. Quantitative continuous variables were presented as the median (percentile 25 to percentile 75) and they were compared using the Mann-Whitney test. Results from the SF-36 were shown by each dimension as previously suggested (Severo et al. 2006). Transcriptions and analysis of interviews were conducted using NVivo 10 software (QSR International, USA, 2013). A content analysis was performed and major themes were identified using constant comparison and category building procedures. For the purpose of the present analysis, interviewees were labelled 1-12. Excerpts from interviews were used to illustrate the findings.

\section{Results}

\section{Participants' description according to the neighbourhood}

The proportion of participation was of $68.9 \%$, and the median of respondents' age is 57.0 years old for both neighbourhoods studied (Table 1). The reasons pointed for non-participation were lack of time and lack of interest. No significant differences were found between populations from both neighbourhoods regarding social and behavioural characteristics such as age, sex, education, work, and others.

\section{House and neighbourhood characteristics and residents' satisfaction}

The major differences among neighbourhoods were found when residents were asked about housing conditions. Satisfaction with house (current and that compared to satisfaction 4 years before; $p<0.001)$, no need for rehabilitation $(p<0.001)$, and absence of mould and dampness in the 
Table 1 Social and behavioural characteristics

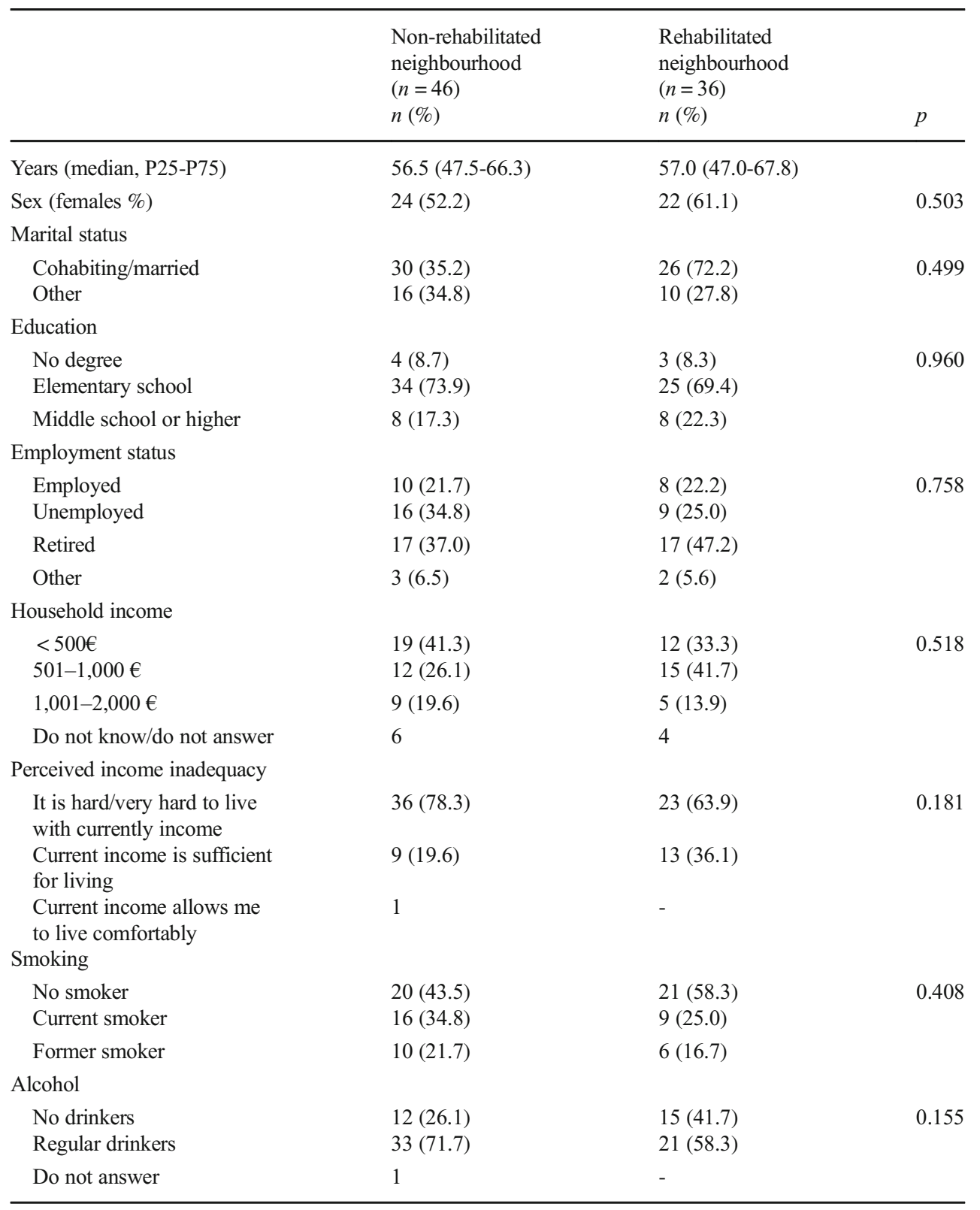

house $(p<0.001)$ as well as pollution and noise $(p<0.05)$ were significantly higher among those from the rehabilitated neighbourhood (Table 2).

\section{Quality of life in social housing and perceived quality of life}

Results from SF-36 were very similar among the two studied neighbourhoods (Table 3). Although no significant statistical differences were found in the SF36, residents from the nonrehabilitated neighbourhood presented higher median scores for "body pain", while residents from the rehabilitated neighbourhood had higher "emotional performance".

\section{Residents' perception of living conditions and quality of life}

The majority of residents were happy with neighbourhood area. First of all, they mention the location within the city and the easy access to several amenities. This neighbourhood is close to the downtown and also to the sea, which was highly valued by residents:

Resident 3 (female): '[...] I really like this area, like pretty much everything, I have everything here close, pharmacy, butcher, supermarket is already here [...] I have everything here, all so close. [...] I like, I really like being here. I sure do.' 
Table 2 House and neighbourhood characteristics and residents' satisfaction
Non-rehabilitated neighbourhood

$n(\%)$

$10(21.7)$

$17(37.0)$

19 (41.3)

Reasonable

satisfaction

Did not change
Decreased

Do not answer

Need for rehabilitation

No

Yes

No answer

The house is dampness free

Disagree

Agree

$32(69.6)$

$11(23.9)$

1

$4(8.7)$

$41(89.1)$

1

44 (95.7)

$2(4.3)$

There is no mould in the house

Disagree

$34(73.9)$

Agree

Do not know

The space in the house is enough Disagree

Agree

$12(26.1)$

$11(23.9)$

$35(76.1)$

The house has sufficient natural light

Disagree

Agree

$2(4.3)$

$44(95.7)$

$\begin{array}{ll}\text { Disagree } & 21(45.7) \\ \text { Agree } & 25(54.3)\end{array}$

A house it is not expensive considering our income Disagree

Agree

Do not know

Neighbourhood

Moved into neighbourhood 26-45 years ago

6-25 years ago

Less than 5 years

Do not know

Is close to open sports space Disagree Agree/totally agree

Pollution and noise in the neighbourhood Agree/totally agree

Vandalism and crime in the neighbourhood Disagree

Agree/totally agree

Insecurity in the neighbourhood

Never

Sometimes

Trust in the neighbours

Not always

Always

Social support by the neighbours

Not always

Always

$8(17.4)$

$37(80.4)$

1

$23(50.0)$

$15(32.6)$

$7(15.2)$

1

$4(8.7)$

$42(91.3)$

$27(58.7)$

$19(41.3)$

$38(84.4)$

7 (15.6)

37 (804)

9 (19.6)

$35(76.1)$

$11(23.9)$

$23(50.0)$

$23(50.0)$

$10(21.7)$

$36(78.3)$

Reciprocity to the neighbours

Not always
Satisfaction with house, compared to 4-year satisfactio

Room temperature is pleasant Disagree

Rehabilitated

neighbourhood

$p$

$n(\%)$

4 (11.

$<0.001$

2 (5.6)

$30(83.3)$

$20(55.6)$

$12(33.3)$

$3(8.3)$

$28(77.8)$

8 (22.2)

$16(44.4)$

20 (55.6)

$5(13.9)$

$30(83.3)$

$4(11.1)$

$32(88.9)$

35 (97.2)

$10(27.8)$

$26(72.2)$

$9(25.0)$

$27(75.0)$

$19(52.8)$

7 (19.4)

$10(27.8)$

$7(20.0)$

$28(80.0)$

29 (80.6)

7 (19.4)

31 (86.1)

5 (13.9)

$<0.001$

$<0.001$

$<0.001$

$<0.001$

0.137

0.707

0.098

0.428

0.703

28 (77.8)

8 (22.2)

0.768

29 (85.3)

0.309

5 (14.7)

$13(36.1)$

23 (63.9)

0.209

$10(27.8)$

$26(72.2)$ 
Resident 7 (male): 'I think [this place] is really good [...] I think this place is a privileged place because we are so close to everything. We are close to downtown, we are close to the beach, the river.'

Resident 11 (female):'It is the place, I love this place, love! I have everything close, supermarkets, buses [...] I tell you, I if had a jackpot I would not move, I'm being honest.'

Resident 12 (female): 'I really like living here. I like. It is quiet, it has a good ambiance. It is very clean ... I like living here very much.'

The mutual help that has characterized these neighbourhoods in the past did not emerge in these interviews. The majority of the residents did not report a close relationship with neighbours:

Resident 5 (female): 'I only enter and leave in my house [...] I only enter and I leave with no conversation with my neighbours although we do not have any problems.'

Resident 4 (female): 'Honestly I do not relate with the people in the neighbourhood [...] I do not relate to anyone, right? Here in my entrance, each one is at their home, we only say good morning, good afternoon or good evening and that's it.'

Resident 3 (female): 'I have no complaints from anyone. Look, I do not even see my neighbours, only if I knock on the door [we see each other]. When I need something from the neighbours I only talk with my neighbour in front, who is always ready to do whatever it takes and I do the same for her. So I do not have anything to say. Also, when I go out [into the neighbourhood] I just walk and I am used to not talking with anyone, so I am quiet, this is true.'

About the housing rehabilitation, the majority of residents reported to be satisfied with the house and the construction work. Most respondents recognized that both building and house have substantially improved with the construction work. They mostly reported improvements in terms of housing conditions but also in terms of security:

Resident 2 (male): There was also some very large projects in terms of improvement. Entrances were closed, they put windows in the little staircase halls, changed the stairways. [...] I am convinced that we have much, much more, much more security with that over there [the entrance door] than when previously we had no such door at the entrance.'

Resident 5 (female): 'Look, the rehabilitation work is good, very good. [...] Before this work the junkies had no problems to come inside the entrance ... But now, we have an entrance door, and they can't come in.'
Resident 8 (male): 'No, I think it's great [...] they closed [the entrance], and did great rehabilitation work. [...] I think the architect had very good taste [...].'

Participants were asked about the main aspects they considered relevant to having quality of life. Two main factors emerged in these interviews: to have health and to have money.

Resident 7 (male):'Quality of life, first of all, is health, is not it? Health is quality of life is health ... so we need to have a house, hygiene, right? To have running water, and sanitation, and everything. But I think that first is our health status, otherwise the other things will not work.'

Resident 4 (female): 'Look quality of life is to have ... what is needed to live. To have a monthly allowance and, to cope with life, but not only! We need to be aware of social problems like pollution. I am very worried with the future of my grandchildren and so.'

Resident 8 (male): 'Everyone says that money does not give you happiness... If we are sick, money does not matter the most ... but, it helps a lot, doesn't it? Besides, the quality of life is health, being healthy and having money at least to eat, right?'

Although most of the interviewees reported having poor health in the questionnaires and also in the interviews, most of them tended to accept their condition and did not complain about their lives:

Resident 7 (male):' I do not complain about my current life, I think it is reasonable, I'm not complaining [...]I am [satisfied], I am, I am. I do not think about having this and that...I do not complain too much, because I see other people and I have friends and everything, and they are much worse than me. They are, they are much worse than me.'

Resident 4 (female): 'I am content with the life I have but sometimes it worries me. I try to control life with the little I have and I only hope "they" don't take from me the little I have. Of course I would like to have, as others have, more for my kids, but I try to have my comfort within our means, of course.'

\section{Discussion}

This study reveals that buildings rehabilitation impacts residents' perception of satisfaction with housing. In general, residents from the rehabilitated neighbourhood are happy with the building improvements and also very happy because they still live in the same neighbourhood. This is a relevant finding 
Table 3 Health status and quality of life SF-36 analysis. Italics denotes median percentiles

\begin{tabular}{|c|c|c|c|}
\hline & $\begin{array}{l}\text { Non-rehabilitated } \\
\text { neighbourhood } n(\%)\end{array}$ & $\begin{array}{l}\text { Rehabilitated } \\
\text { neighbourhood } n(\%)\end{array}$ & $p$ \\
\hline \multicolumn{4}{|l|}{ Perceived health status } \\
\hline Very bad/bad & $10(21.2)$ & $10(27.8)$ & \multirow[t]{4}{*}{0.540} \\
\hline Reasonable & $26(56.5)$ & $22(61.1)$ & \\
\hline Very good/good & $9(19.6)$ & $4(11.1)$ & \\
\hline Do not answer & 1 & - & \\
\hline \multicolumn{4}{|l|}{ Doctor diagnosis of chronic diseases } \\
\hline No & $18(39.1)$ & 15 (41.7) & \multirow[t]{3}{*}{0.713} \\
\hline Yes & $27(58.7)$ & $19(52.8)$ & \\
\hline Do not know & 1 & 2 & \\
\hline \multicolumn{4}{|l|}{ Visits to the doctor } \\
\hline$<3$ times/last year & $22(47.8)$ & $13(36.1)$ & \multirow[t]{4}{*}{0.412} \\
\hline $3-10$ times/last year & $15(32.6)$ & $13(36.1)$ & \\
\hline$>10$ times/last year & $4(8.7)$ & $6(16.7)$ & \\
\hline Do not know & 5 & 4 & \\
\hline \multicolumn{4}{|l|}{ Medication use (last 12 months) } \\
\hline No & $10(21.7)$ & $7(19.4)$ & \multirow[t]{3}{*}{0.760} \\
\hline Yes & $35(76.1)$ & $29(80.6)$ & \\
\hline Do not know & 1 & - & \\
\hline \multicolumn{4}{|l|}{ Sick building syndrome } \\
\hline No & $30(65.2)$ & $28(77.8)$ & \multirow[t]{3}{*}{0.200} \\
\hline Yes & $12(26.1)$ & $6(16.7)$ & \\
\hline Do not know & 4 & 2 & \\
\hline SF-36 & Median (P25-P75) & Median (P25-P75) & \\
\hline Physical functioning & $85.0(53.8-95.0)$ & $85.0(45.3-95.0)$ & 0.783 \\
\hline Physical performance & $75.0(0.0-100.0)$ & $75.0(0.0-100.0)$ & 0.564 \\
\hline Body pain & $72.0(32.0-100.0)$ & $52.0(22.0-100.0)$ & 0.208 \\
\hline General health & $65.0(48.8-80.0)$ & $60.0(27.5-75.0)$ & 0.633 \\
\hline Vitality & $47.5(40.0-60.0)$ & $50.0(45.0-56.0)$ & 0.532 \\
\hline Social functioning & $100.0(71.9-100.0)$ & $100.0(62.5-100.0)$ & 0.402 \\
\hline Emotional performance & $66.7(0.0-100.0)$ & $100.0(0.0-100.0)$ & 0.273 \\
\hline Mental health & $72.0(55.0-89.0)$ & $62.0(40.0-80.0)$ & 0.598 \\
\hline Physical health (average score) ${ }^{\mathrm{a}}$ & $54.3(43.4-57.8)$ & $51.6(38.7-59.0)$ & 0.448 \\
\hline Mental health (average score) ${ }^{\mathrm{b}}$ & $49.8(43.5-57.2)$ & $47.8(41.5-55.3)$ & 0.448 \\
\hline
\end{tabular}

${ }^{\text {a }}$ Physical health was assessed via four dimensions, representing physical functioning (the extent to which health limits physical activities), physical performance (the extent to which physical health interferes with work or other daily activities), body pain (the intensity of pain and the effect of pain on normal work, both inside and outside the home), and general health (personal evaluations of current health, health outlook, and resistance to illness)

${ }^{\mathrm{b}}$ Mental health was assessed via four dimensions, representing vitality (feeling full of energy rather than tired and worn out), social functioning (the extent to which physical health or emotional problems interfere with normal social activities), emotional performance (the extent to which emotional problems interfere with work or daily activities) and mental health (mental health including depression, anxiety behavioral-emotional control and general positive effect) as the rehabilitation program is dependent on the public funding, and in the context of financial restraints, it is important that the program proves to be associated with wellbeing.

No statistical significant differences were found among the two neighbourhoods concerning sociodemographic characteristics, which shows that differences found between these two populations are not due to differences in sex, age, education or income. Although we were not able to identify improvements in quality of life or health indicators regarding residents from the rehabilitated houses, the differences between the two neighbourhoods are well expressed in variables such as satisfaction with the housing (currently and compared to 4-year satisfaction, i.e. before rehabilitation work), the need for rehabilitation work and regarding the presence of dampness and mould in the house. 
No statistical significant results were found in the SF36 dimensions between neighbourhoods. Also, beta coefficients were calculated and a linear regression model was undertaken although no different results were foundTable S1 of electronic supplementary material (ESM). Due to the small sample size, we opted to present results using descriptive analysis; however, results from the qualitative interviews showed that people define quality of life as being healthy and having money mostly for health expenses. In general, people tended not to complain about their lives although they recognized their own limitations and needs. This result also reveals some scepticism and conformism among the residents. Their perspectives show that people do not expect things to get better but only hope that life does not get any worse. Although not directly approached in our study, we can speculate that this negative view of life might be related with the recent Portuguese economic uncertainty (Martin-Carrasco et al. 2016).

There are some indoor environmental hazards such as biological and chemical contaminants, poor ergonomics, lighting, and physical design, that may cause or exacerbate health problems such as asthma, allergies or lung cancer (Fernandes et al. 2009; Ncube and Riffat 2012; Wu et al. 2007). These health conditions are potentially preventable. In this case, residents from rehabilitated neighbourhoods refer to the non-existence of dampness $(55.6 \%)$ and mould $(83.3 \%)$ in the houses; and clearly and repeatedly reported it to be associated with the rehabilitation work in the buildings. Residents recognize and are satisfied with their homes in the rehabilitated neighbourhood. With these results we are able to support that justifying the need of improvements in neighbourhoods with an elderly population should take several factors into account and not only just look at specific indicators. Building rehabilitation helps to avoid uprooting people from their places of residence, which seems to be understood as a loss of identity. A previous study conducted in the United States showed that improvements found from relocating does reduce some stressors, but the health costs of uprooting may offset any benefits (Keene and Geronimus 2011). Although few studies addressed the impact of relocation on health, there is evidence that residents' health seems to be worsening rapidly over time (Kleit and Manzo 2006), mainly among the older people who have a greater sense of place (Tester et al. 2011).

It has been described elsewhere that residents from old neighbourhoods complained about the loss of amenities and services, like post offices and bakeries that have been replaced by others that do not appeal to the older people (Milton et al. 2015). However, our participants underline the fact that all services and amenities such as pharmacies, bakeries, grocery shops, are in a short distance from home, as well as public transportation and open space sports. Regardless of the fact that individual's negative perceptions of their neighbourhood present lower levels of wellbeing (Toma et al. 2015), it is important to point out that residents from both studied neighbourhoods are happy with the location of their neighbourhood. Our results emphasize the satisfaction of residents from the rehabilitated buildings, meaning that more important than the rehabilitation work is the fact of not being relocated.

It has been actively defended that demolition of public housing might be justified in part by the presumed social pathologies of social housing (Oakley and Burchfield 2009; Popkin and Cunningham 2002); however, our findings are in line with other authors (Keene and Geronimus 2011), suggesting that residents are satisfied with the place where they live and with the neighbourhood. Nonetheless, residents from the non-rehabilitated neighbourhoods claim they need rehabilitation work and complain of the dampness and mould. So, the large social housing rehabilitation program currently ongoing in Porto is in line with the theory defended elsewhere (Tester et al. 2011), and takes into account the sense of place developed by some residents and uses it as a resource for renovating and revitalizing social housing communities rather than demolishing them and relocating residents to other neighbourhoods. In fact, it has been defended that interventions designed to improve health and wellbeing of residents of social housing neighbourhoods could promote a stronger sense of cohesion amongst residents (De Jesus et al. 2010). What has emerged from interviews is that residents from the rehabilitated neighbourhoods feel safe and they like the place they live and do not want to live elsewhere. It is also significant to mention the fact that although social housing neighbourhoods are often associated with social disorder and high rates of crime and vandalism (Jargowsky 2001; Tester et al. 2011), most of our residents never felt insecure within the neighbourhood, stating, in both rehabilitated and nonrehabilitated neighbourhoods, that there is no crime nor vandalism in their neighbourhood. The feeling of security seems to be a significant and valuable factor for the residents.

There are some limitations that must be taken into consideration that might clarify the fact that finding significant differences in the health status among these two groups of residents was not expected. Firstly, the improvements were made only 4 years before the questionnaire which may not be enough time to show an impact on health status; secondly, we cannot disregard the fact that if we conducted a medical examination or spirometry check we could have different results, and thirdly, most of the residents are old and therefore they have all the comorbidities associated with ageing, and even in the best conditions they would be complaining about their health. Accordingly to Census 2011, the aging of the population during the past decade, was generalized throughout the country. Particularly in the northern region where the studied neighbourhoods are located, the aging index rose from 79.8 seniors per 100 young people in 2001 to 113.3 per 100 in 2011 (INE 2012). Also, our study limited the analysis to only 
two neighbourhoods. We compared the population from houses that had experienced rehabilitation and others who have not and are still in the original structure since first construction in early 1970. The sampled houses had measurement data taken during the year and it would not be possible to get these measurements in a study with a larger number of houses (Soares et al. 2015). We are aware of the limitations on the sample size but we believe that the results are representative of the social housing residents' reality in Porto.

We should note that there are other health aspects that we could measure in our population, particularly in a more objective way. Future studies should measure, for instance, respiratory conditions through spirometry besides assessing wellbeing through a questionnaire. Additionally, we believe that a strength of our study relies on the combined approach of the quantitative with qualitative data in order to betterinterpret ourresults.

It is imperative that future social housing policies comprise the rehabilitation of older neighbourhoods. Our results suggest that public economic and financing resources should be redirected to social housing rehabilitation. A protocol of identification and remediation of hazards across all the neighbourhoods managed and maintained by public funding should be developed and implemented locally. Additionally, community interventions to improve knowledge and disseminate information on the public health risks associated with indoor environments should also be implemented.

It is important to have a multiple level approach and a concerted policy change in order to achieve healthy indoor environments. Indeed, although in short term the rehabilitation does not seem to have a direct impact on health savings and increased productivity for the occupants, it is an important dimension of wellbeing and residents sense of satisfaction that may certainly outweigh the costs of building maintenance.

Acknowledgements Authors are grateful to DomusSocial, E.M. for availability and collaboration.

Funding This work is supported by FEDER funding from the Operational Programme Factors of Competitiveness - COMPETE and by national funding from the FCT - Foundation for Science and Technology (Portuguese Ministry of Education and Science) within the project "Influence of Indoor Hygrothermal Conditions on Human Quality of Life in Social Housing" (ref. EXPL/ECM-COM/1999/2013-FCOMP01-0124-FEDER-041748). SF and SS acknowledge the FCT (SFRH/BPD/97015/2013 to SF and SFRH/BD/108742/2015 to SS). The ISPUP-EPIUnit, Universidade do Porto, Portugal (UID/DTP/ $04750 / 2013$ ) is funded by the FCT.

\section{Compliance with ethical standards}

Conflict of interests The authors declare that they have no conflict of interest.

Informed consent Informed consent was obtained from all individual participants included in the study.

\section{References}

Bluyssen PM, Cox C (2002) Indoor environment quality and upgrading of European office buildings. Energy Build 34(2):155-162. doi:10.1016/S0378-7788(01)00101-3

Brasche S, Bischof W (2005) Daily time spent indoors in German homes: baseline data for the assessment of indoor exposure of German occupants. Int J Hyg Environ Health 208(4):247-53. doi:10.1016/j. ijheh.2005.03.003

De Jesus M, Puleo E, Shelton RC, Emmons KM (2010) Associations between perceived social environment and neighborhood safety: health implications. Health Place 16(5):1007-1013. doi:10.1016/j. healthplace.2010.06.005

Doman'ski H, Ostrowska A, Przybysz D, Romaniuk A, Krieger H (2006) First European quality of life survey: social dimensions of housing. Eurofound, Brussels

Eurofound (2006) Social dimensions of housing in the European Union. Eurofound, Brussels

Fernandes E, Jantunen M, Carrer P, O S, Harrison P, Kephalopoulos S (2009) EnVIE: co-ordination action on indoor air quality and health effects. http://cordis.europa.eu/documents/documentlibrary/126459681EN6. pdf. Accessed July 2016

Greenbaum S (2002) Report from the field: social capital and deconcentration - theoretical and policy paradoxes of the HOPE VI program. North Am Dialogue 5(1):9-13. doi:10.1525/nad.2002.5.1.9

Hopton JL, Hunt SM (1996) Housing conditions and mental health in a disadvantaged area in Scotland. J Epidemiol Community Health 50(1):56-61

INE (2012) Censos 2011 resultados definitivos: região Norte. Instituto Nacional de Estatística, I.P., Lisbon

Jargowsky PA (2001) Sprawl, concentration of poverty, and urban inequality In: Squires G (ed) Urban sprawl: causes, consequences and policy responses. Urban Institute, Washington, DC, $47 \mathrm{pp}$

Keene D, Geronimus A (2011) Community-based support among African American public housing residents. J Urban Health 88(1): 41-53. doi:10.1007/s11524-010-9511-z

Kleit RG, Manzo LC (2006) To move or not to move: relationships to place and relocation choices in HOPE VI. Housing Pol Debate 17(2):271-308. doi:10.1080/10511482.2006.9521571

Martin-Carrasco M, Evans-Lacko S, Dom G, Christodoulou NG, Samochowiec J, Gonzalez-Fraile E, Bienkowski P, GomezBeneyto M, Dos Santos MJ, Wasserman D (2016) EPA guidance on mental health and economic crises in Europe. Eur Arch Psychiatry Clin Neurosci 266(2):89-124. doi:10.1007/s00406016-0681-x

Milton S, Pliakas T, Hawkesworth S, Nanchahal K, Grundy C, Amuzu A, Casas JP, Lock K (2015) A qualitative geographical information systems approach to explore how older people over 70 years interact with and define their neighbourhood environment. Health Place 36: 127-133. doi:10.1016/j.healthplace.2015.10.002

Molhave L, Krzyzanowski M (2000) The right to healthy indoor air. Indoor Air 10(4):211

Muhič S, Butala V (2004) The influence of indoor environment in office buildings on their occupants: expected-unexpected. Build Environ 39(3):289-296. doi:10.1016/j.buildenv.2003.09.011

Ncube M, Riffat S (2012) Developing an indoor environment quality tool for assessment of mechanically ventilated office buildings in the UK: a preliminary study. Build Environ 53(0):26-33. doi:10.1016 /j.buildenv.2012.01.003

Northridge J, Ramirez O, Stingone J, Claudio L (2010) The role of housing type and housing quality in urban children with asthma. J Urban Health 87(2):211-224. doi:10.1007/s11524-009-9404-1

Oakley D, Burchfield K (2009) Out of the projects, still in the hood: the spatial constraints on public-housing residents' relocation in 
Chicago. J Urban Affairs 31(5):589-614. doi:10.1111/j.14679906.2009.00454.x

Popkin S, Cunningham M (2002) CHA relocation counseling assessment final report. The Urban Institute, Metropolitan Housing and Communities Center, Washington, DC

QSR International Pty Ltd. NVivo qualitative data analysis Software. Version 10, 2013

Ruel E, Oakley D, Wilson GE, Maddox R (2010) Is public housing the cause of poor health or a safety net for the unhealthy poor? J Urban Health 87(5):827-838. doi:10.1007/s11524-010-9484-y

Severo M, Santos AC, Lopes C, Barros H (2006) Reliability and validity in measuring physical and mental health construct of the Portuguese version of MOS SF-36. Acta Med Port 19(4):281-287

Soares S, Fraga S, Delgado J, Ramos N (2015) Influence of indoor hygrothermal conditions on human quality of life in social housing: a study protocol. J Public Health Res. doi:10.4081/jphr.2015.589

Soloman R (2005) Public housing reform and voucher success: progress and challenges. The Brookings Institution Metropolitan Policy Program, The Brookings Institute, Washington, DC
Tester G, Ruel E, Anderson A, Reitzes D, Oakley D (2011) Sense of place among Atlanta public housing residents. J Urban Health 88(3):436453. doi:10.1007/s11524-011-9579-0

Thomson H, Petticrew M, Morrison D (2001) Health effects of housing improvement: systematic review of intervention studies. 323(7306): 187-190 doi:10.1136/bmj.323.7306.187

Toma A, Hamer M, Shankar A (2015) Associations between neighborhood perceptions and mental well-being among older adults. Health Place 34:46-53. doi:10.1016/j.healthplace.2015.03.014

Ware J, Sherbourne C (1992) The MOS 36-item short-form health survey (SF-36). I. Conceptual framework and item selection. Med Care 30: 473-483

Wilkinson D (1999) Poor housing and Ill health: a summary of research evidence. The Scottish Office, Edinburgh

Wu F, Jacobs D, Mitchell C, Miller D, Karol MH (2007) Improving indoor environmental quality for public health: impediments and policy recommendations. Environ Health Perspect 115(6):953957. doi:10.1289/ehp. 8986 